Proc. Indian Acad. Sci. (Earth Planet. Sci.), Vol. 93, No. 2, July 1984, pp. 159-176.

(C) Printed in India.

\title{
Magnetometric surveys over some iron-ore occurrences in the Eastern Ghats belt of Godavari Districts, Andhra Pradesh
}

\author{
V BHASKARA RAO and A LAKSHMIPATHI RAJU \\ Department of Geophysics, Andhra University, Visakhapatnam 530003, India
}

MS received 21 December 1982; revised 31 January 1984

\begin{abstract}
Iron-ore with magnetite as the chief ore mineral occurs in the Precambrians of Eastern Ghats. Vertical magnetometric surveys were carried out to delineate some of the ore bands, in the Ghats belt of Godavari Districts, Andhra Pradesh, around Addatigala, Devipatnam and Tekuru. Interpretation of the magnetic anomalies was based on the tabular models. Ore bands are at shallow depths of around $5 \mathrm{~m}$. The deduced inclinations of magnetisation suggest that the magnetisation is largely remanent. The intensities of magnetisation are in the range of 5 to $10.5 \times 10^{-3}$ emu and agree well with the laboratory measurements on the ore samples. At Devipatnam and Tekuru the magnetic background seems to be high. At Tekuru the ore band appears to be very limited in depth extent. The limited depth extent coupled with high magnetic background explains the anomaly which is not so prominent. It is concluded that in such areas, it is only the high grade magnetite ore bands of considerable depth extent that can be successfully delineated by the magnetic method.
\end{abstract}

Keywords. Iron-ore; Eastern Ghats; magnetometric surveys; magnetic anomalies.

\section{Introduction}

Geophysical literature abounds with examples of magnetometric surveys for discovery of iron-ores. Some early investigations (like Broderick 1918; Barnes and Romberg 1943) are based on dip-needle and dial-compass observations. In general, investigations for iron ore come mainly under two categories - one in search of ores with magnetite as the major ore mineral and another in search of enriched haematite ores. In the former the deposits may be detected directly by the magnetic method, while in the latter the method serves as an indirect guide (the anomaly being dependant, among other things, on the degree of oxidation). In the first category mention may be made of prospecting for iron-ore in Jamaica (Vincenz 1955), investigations on the Biwabik iron formation in Minnesota (Bath 1962), vertical magnetic investigations over magnetite serpentinite of the 'Moutague Du Sorceier' (Gaucher 1965), discovery of iron-ore deposits in Missouri, Ontario and Pennsylvania (George 1967) Dayton iron-ore deposits in Nevada (Paul 1967), the search for iron-ore on Eyre peninsula of South Australia (Mumme 1963; Webb 1967), the work of GsI in Punjab State (Paul et al 1971), vertical magnetic surveys over quartz magnetite bands in Andhra Pradesh (Rao and Murty 1967; Rao et al 1974) and on the magnetite deposits in Palmau District of Bihar (Singh and Avadh Ram 1971). Investigations over ilmenite-haematite deposits in Eastern Quebec (Bourret 1949), the multimillion ton ore bodies in Marcona Mining District of Peru (Gay 1967), the Shefferville iron-ore deposits in Northern Canada (Seguin 1968, 1971) are some of the other category.

The Precambrians of the Eastern Ghats belt are a potential source of iron-ore. Sriramadas (1961) opines that the discovery of these deposits is delayed probably due to 
the inaccessibility of the agency tracts. Magnetometric surveying was done (Lakshmipati Raju 1977) along with laboratory investigations, as an attempt to delineate some of the ore occurrences in the Ghats belt of Godavari Districts in Andhra Pradesh.

\section{Geological aspects}

In Andhra Pradesh most of the iron-ore deposits are found in the Dharwar or the Purana formations. Some low grade ores are also known to occur in the Upper Gondwanas and in the laterite cappings of the deccan traps. The lodes are generally found in the fracture zones of the Archaean rocks. The bedded deposits, mostly banded-haematite-quartzites, occur within Dharwars and Cuddapahs. The detrital ores derived from weathering and transportation of the pre-existing deposits are of comparatively limited distribution. In the Precambrians of Eastern Ghats iron-ores occur with magnetite as the chief ore-mineral. According to Ray (1967) the Eastern Ghats region is a portion of the oldest precambrian crust in India. Khondalites of the granulite facies have charnockites as their almost constant companion. Granitic gneisses and anorthosites prevail in many parts.

The iron-ore occurrences covered by the present study are distributed around Addatigala, Devipatnam and Tekuru (figure 1). They are at comparatively high elevations in the rugged hill ranges which have an average elevation of about $670 \mathrm{~m}$ above msl with few intervening valleys across. The hill slopes are usually covered with thick talus and soil supporting thick vegetation and impenetrable forests. At Addatigala the ore is associated with a sequence of mafic and ultramafic rocks comprising of variants of pyroxene-hornblende and plagioclase within which magnetite occurs as bands and lenses. The country rocks comprise garnetiferous granite gneisses, garnet-feldspar-sillimanite gneisses, reconstituted quartz feldspar gneisses and schists, feldspar-sillimanite gneisses of the khondalite series, charnockites, hornblende gabbro, norite, pyroxenite and amphibolite of the charnockite series and pegmatites. On Vangukonda hill (figure 2) the ore occurs as a band trending $\mathrm{N} 60^{\circ} \mathrm{E}$

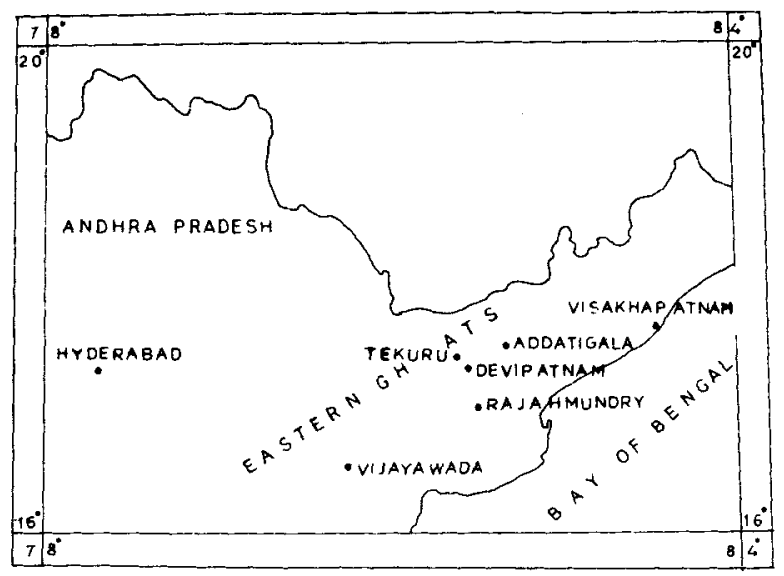

Figure 1. Index map. 


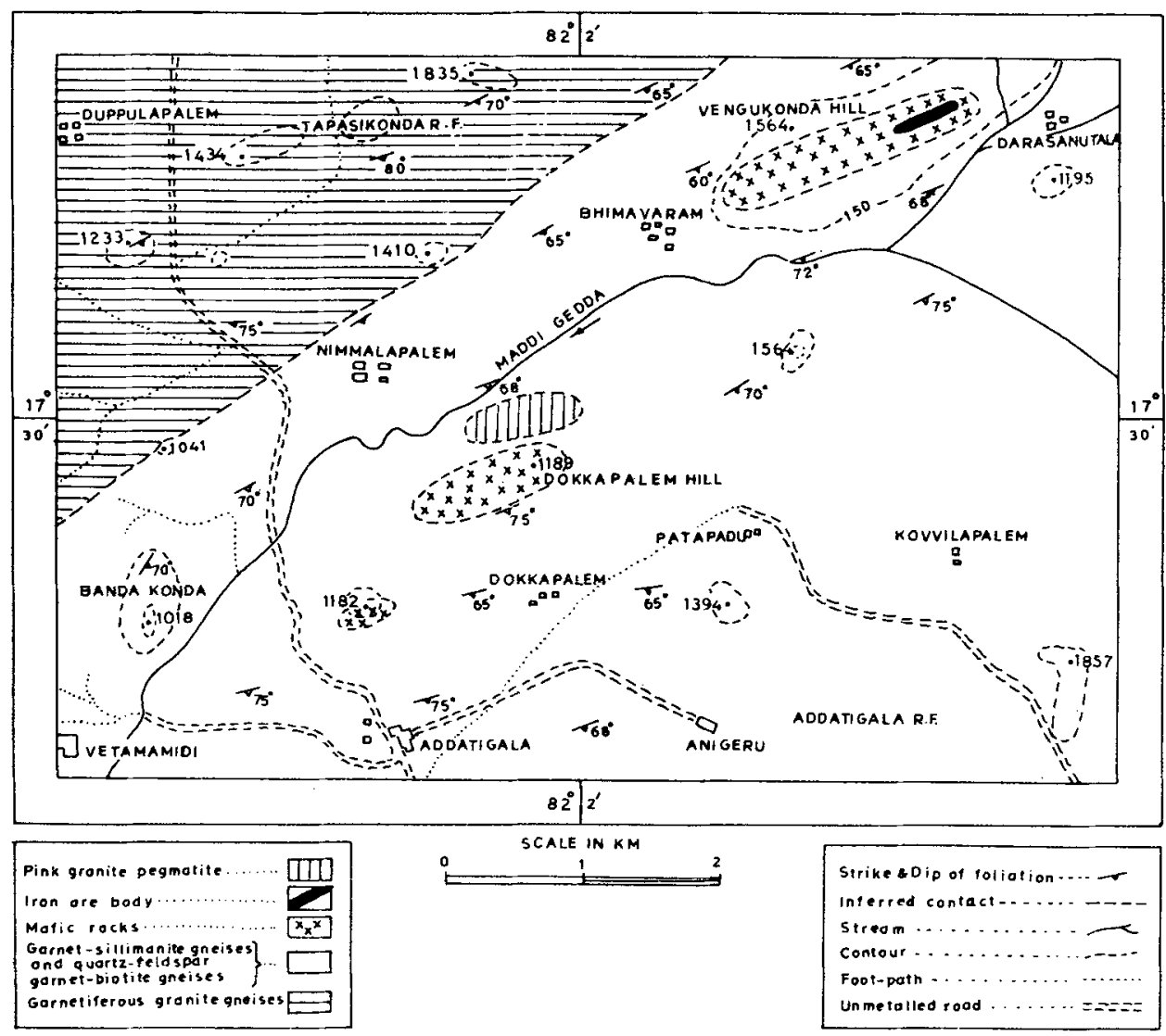

Figure 2. Geological map of Addatigala area.

with a dip of $60^{\circ} \mathrm{SE}$. Relationship of the ore band with the country rock gneisses indicates a conformable nature. The pyroxenites and gabbros of the charnockite series form the hanging wall as well as the foot wall. At Devipatnam magnetite is associated with ultramafic and mafic rocks comprising pyroxenites and gabbros. The country rocks are khondalite gneisses and schists, garnetiferous quartzites, quartzites, charnockites, gabbros, leptynites and pegmatites. The khondalite series strike NE-sw and EW with steep dips. The charnockites and pegmatites cut across the khondalite series. Pyroxenites and gabbros occur as thin bands and layers in conformable relationship with the enclosing paragneisses. The magnetite ore occurs as reefs and veins in association with quartz and feldspar of the pegmatite and khondalite series. The Siddeswara konda ore band (D1 and D2 in figure 3) strikes EW with nearly vertical dip. The Lingavaram ore band (figure 3, D3) strikes at $\mathrm{N} 150^{\circ} \mathrm{E}$ with vertical dip. The country rocks at Tekuru are khondalites consisting of garnet sillimanite gneisses, garnet-sillimanite-feldspar gneisses, biotite-feldspar-quartz schists, garnetiferous quartzites, quartzites, charnockitic rocks containing diorites and pegmatites. The exact nature of the relationship of the ore band on Enukonda hill (figure 3) with the host rock is not observable due to thick soil cover. 


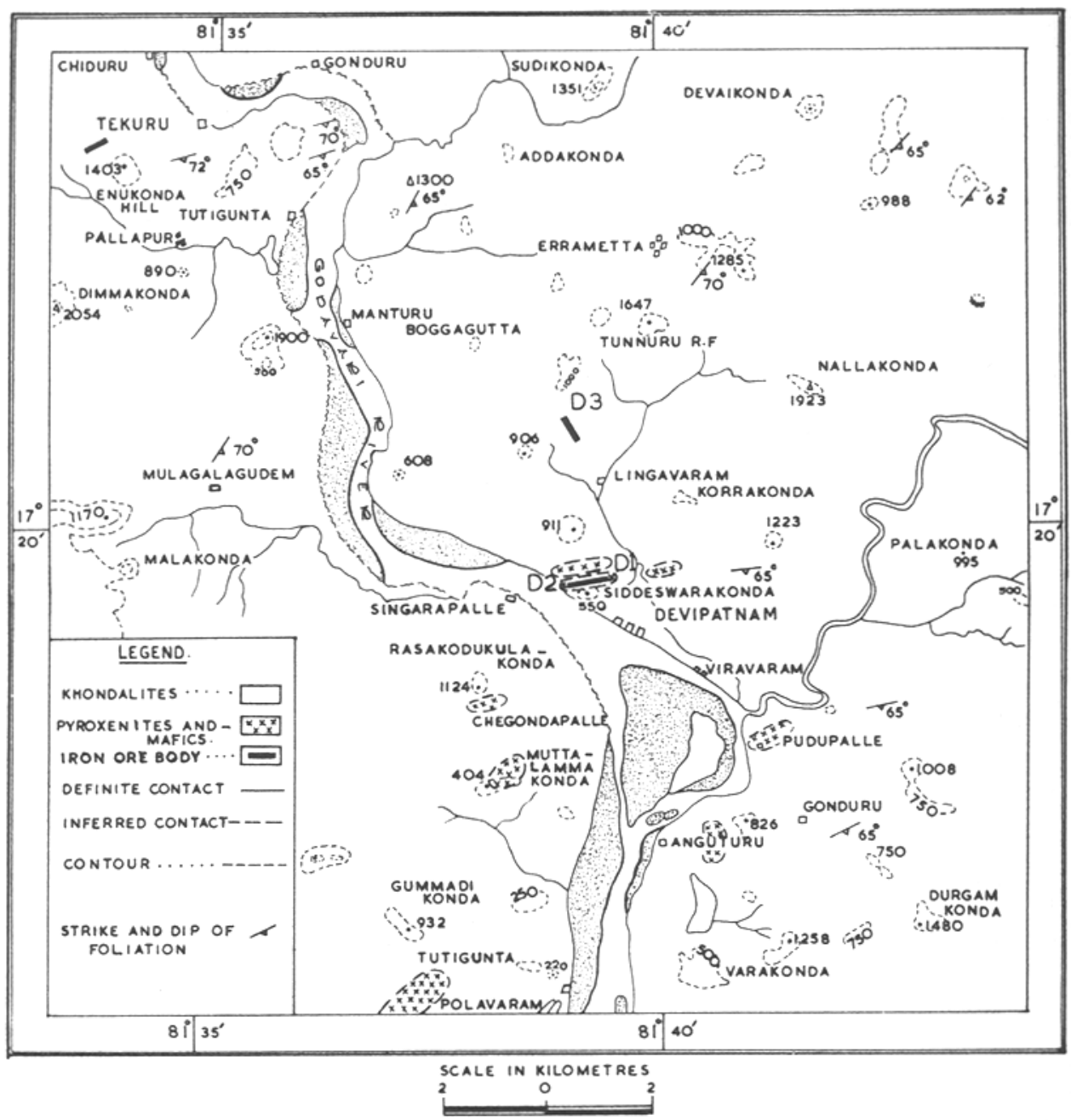

Figure 3. Geological map of Devipatnam-Tekuru area (After Narasayya 1970).

\section{Magnetometric survey}

The limiting factors for the layout of the present survey are vegetation and topography. The traverses are, however, long enough to include the entire anomaly due to the ore body. The traverses were laid perpendicular to the strike of the country rock formations as the ore bands have a conformable relationship. Vertical magnetic field observations were made with a torsion magnetometer (Askania Werke make) which has a scale value of 250 gammas. Observations in a regular fashion were made around altogether five localities. They were referred to observations at Base Station for purposes of data reduction.

\section{Interpretation procedures}

Iron ore in the areas of investigation occurs as bands. The vertical magnetic anomaly patterns and profiles over them resemble those of tabular bodies. So, the anomalies in 
most cases are interpreted on the basis of an infinite dyke model. Bodies with infinite dimensions, as such, do not exist in nature. But Koulomzine et al (1970) found that when a dyke has a length of more than ten times its width or depth to top (which ever is greatest) and a similar extent in depth, the conditions tend towards the limiting case of an infinite dyke. If the magnetisation is entirely down-dip the anomaly on a central profile across the strike of a short dyke will be reasonably similar to the infinite dyke profile (Hutchison 1958). Bath (1962) found that for a thin vertical sheet a strike length of eight depth units will be effectively infinite for considerations of anomaly amplitude.

There are many methods of interpretation based on the dyke model. Mention may be made of the geometric methods of Egyed (1948), Jung (1953) and Powell (1967), type curves of Cook (1950), the curve matching method of Gay (1963) the graphical methods of Koulomzine and Masse (1947), Vacquier et al (1951), Bruckshaw and Kunaratnam (1963) and Moo (1965), separate interpretations of symmetric and antisymmetric components of a dyke anomaly by Hutchison (1958) and Koulomzine et al (1970) and the single gradient case of Bean (1966). Interpretation of thin dyke anomalies has been attempted by Reford (1964); Grant and West (1965) and Banerjee (1972) among others. The prism anomalies were tackled by Bhattacharya $(1964,1966)$, Grant and Martin (1966), Sharma (1966) and others.

For interpreting the infinite dyke anomaly the method of Koulomzine et al (1970) was adopted because of the ease with which it can be used and its 'freedom from special assumptions' (Grant 1972). For a thin dyke of finite depth extent the method of Banerjee (1972) was used. For the prism model theoretical curves suitable to the field situation were computed and matched with the field curve.

\section{Magnetic anomalies and their interpretation}

In the Addatigala area magnetometric observations were made, on the flank of Vangukonda hill, along straight traverses, at $30 \mathrm{~m}$ intervals, at $\mathrm{N} 330^{\circ} \mathrm{E}$ with stations at $6 \mathrm{~m}$ intervals. The resulting anomalies were contoured and are shown in figure 4 . The prominent anomalies observed are of the order of $2500 \gamma \mathrm{s}, 6000 \gamma \mathrm{s}$ and $-2500 \gamma \mathrm{s}$ at $P, S$ and $M$ respectively. The high anomaly at $S$ is believed to be due to the iron-ore section seen projecting from the hanging wall of the abandoned mining pit. The principal profile $A B$ (figure 5) was interpreted for the dimensions of the ore body. It runs across the anomaly feature at $P$, roughly SE to NW. Its northwest limb is disturbed probably because of a weak minimum. It was split into symmetric and antisymmetric components. The antisymmetric component $A(x)$, as can be seen from figure 5 , is far less in amplitude than the symmetric component, $S(x)$. The depth and width are obtained based on the information from symmetric component and they are $10.7 \mathrm{~m}$ and $27.1 \mathrm{~m}$ respectively with $Q$, the angle made by the magnetisation with the ore band in the profile plane as $19^{\circ}$. With these parameters a theoretical dyke anomaly was computed and shown as a discontinuous line in the figure. Matching the field curve with the theoretical one gives $8.6 \times 10^{-3} \mathrm{emu}$ for the intensity of magnetisation.

In the Devipatnam area the magnetometric survey was carried out at three places. Two of them, D1 and D2 (figure 3) separated by $1 \mathrm{~km}$, are by the side of Siddeswara Konda hill and the third, D3 is near Lingavaram. At D1 traverses were laid at $\mathrm{N} 315^{\circ} \mathrm{E}$ at intervals of $5 \mathrm{~m}$. On all the traverses stations were spaced at $1.5 \mathrm{~m}$. At D2 traverses were laid at $\mathrm{N} 340^{\circ} \mathrm{E}$ at an interval of $8 \mathrm{~m}$ with stations at $1.5 \mathrm{~m}$ intervals. The 


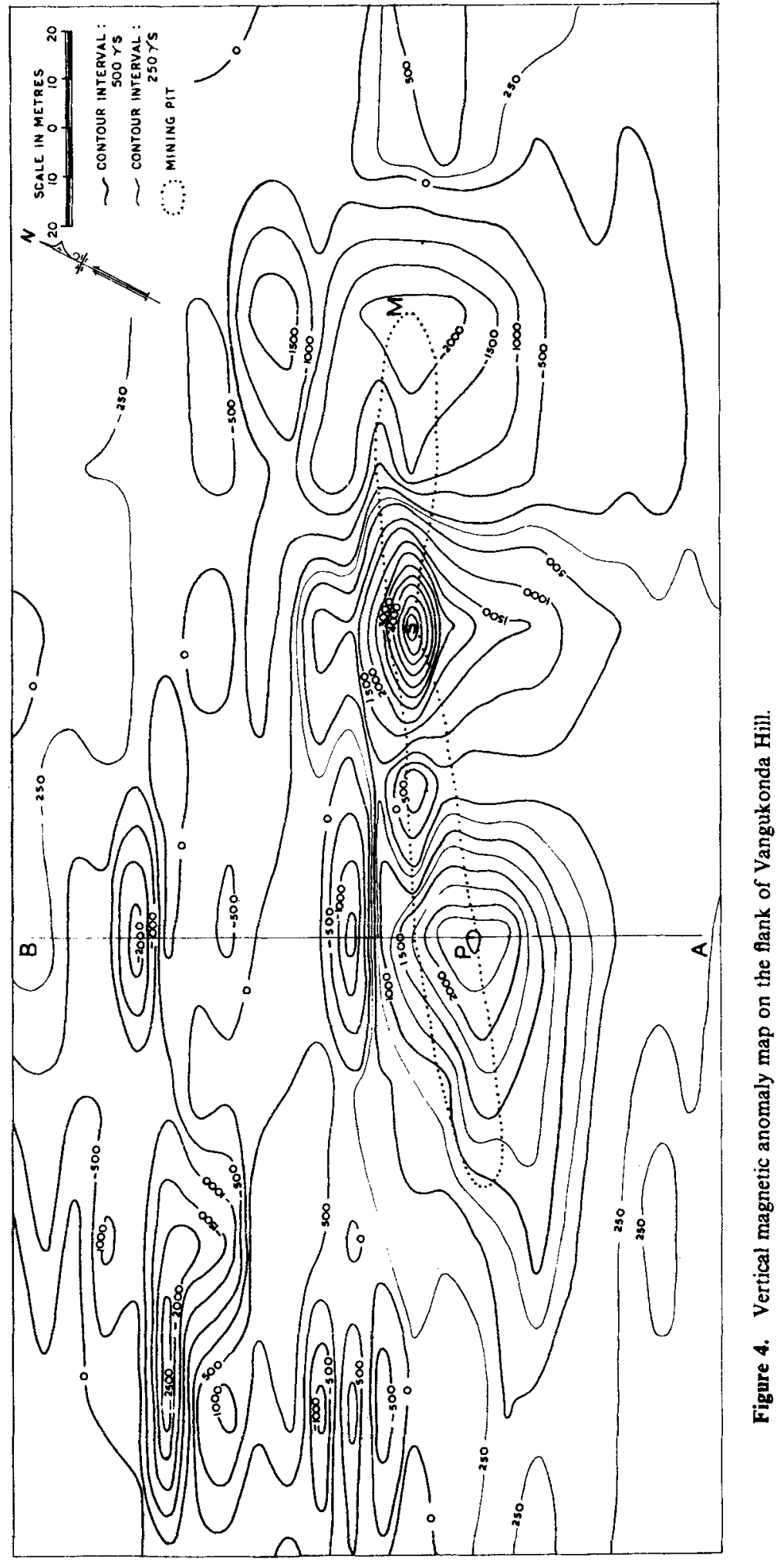




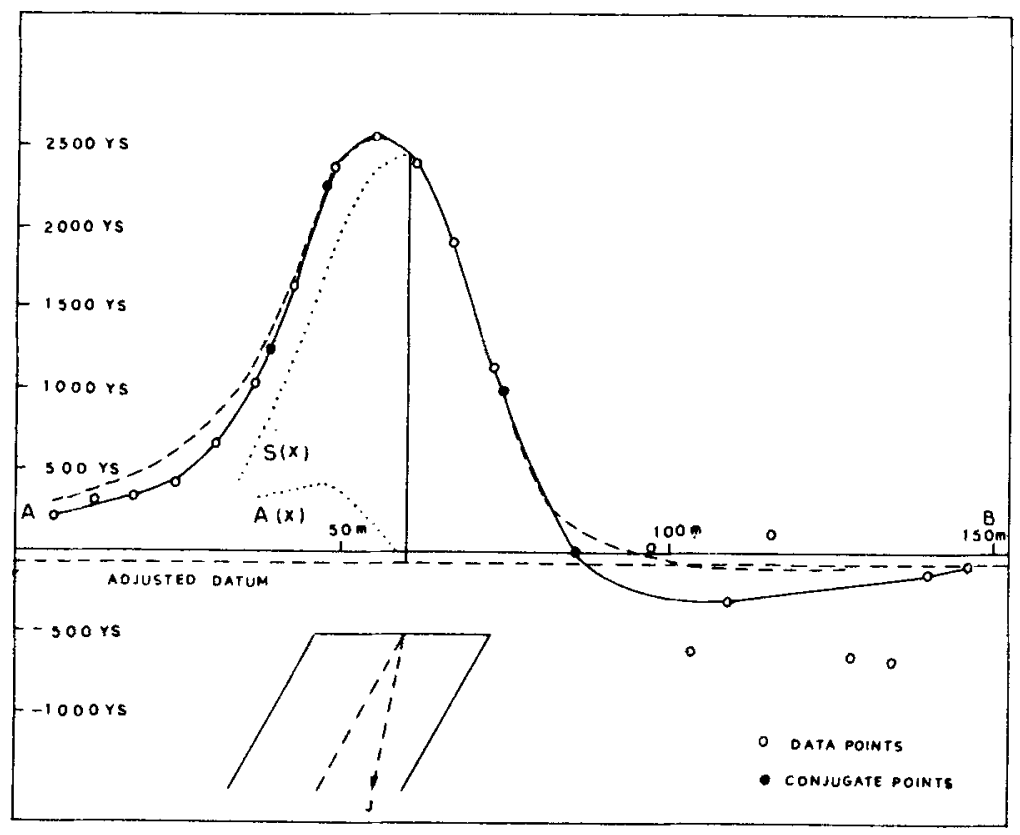

Figure 5. Profile AB.

anomalies are shown contoured separately in figures 6 and 7. The vertical magnetic anomaly contours in figure 6 are smooth and present a clear pattern delineating the ore body. The apparently undisturbed nature of the anomaly pattern may be ascribed to fairly uniform magnetisation in the ore band as well as in the host rock. At the centre of the map, marked A, a maximum of $2300 \gamma \mathrm{s}$ was observed. Towards the north a minimum of $2600 \gamma \mathrm{s}$ was observed at B. Towards the sw a positive high is present probably indicating an extension of the ore band. The anomaly pattern at D2 (figure 7) does not appear to be as simple as at D1. Towards SE there is a narrow and extending anomaly band at A (figure 7). A closure of $2000 \gamma \mathrm{s}$ is in juxtaposition. At B and C contours of bipolar nature are present. They appear to constitute a trend. The anomaly band at $A$ may be indicative of an elongated ore band in the form of a vein. Towards NE the ore body seems to extend with a decreased anomaly amplitude consequent perhaps to the increasing thickness of the overburden. It appears that the mineralisation is in two branches which slightly diverge from each other towards sw.

At D3, near Lingavaram, the traverse lines were laid at $\mathrm{N} 60^{\circ} \mathrm{E}$ spaced at $30 \mathrm{~m}$ with stations at $6 \mathrm{~m}$ intervals. The anomaly map is given in figure 8 . It depicts an elongated positive contour pattern at $A$, a more or less rounded positive contour pattern at $B$ and a negative centre towards north at $\mathrm{C}$. At $\mathrm{A}$ the maximum anomaly observed was $7400 \gamma \mathrm{s}$ while at B it was $6200 \gamma \mathrm{s}$. The minimum at $C$ has a magnitude of $2700 \gamma \mathrm{s}$. The major contour elongation may be delineating the ore body. At $\mathrm{B}$ the low gradient indicates either a deep seated ore clot or a mineral concentration in the host rock.

Three profiles, one each from the anomaly maps at D1, D2 and D3, were analysed. Profile CD (figure 9) is across the anomaly pattern in figure 6 and runs roughly from SE to $\mathrm{NW}$. It was split into its symmetric and antisymmetric components and independent estimates of depth, width and $Q$ were made from both. The average values of $2 \cdot 1 \mathrm{~m}, 6 \mathrm{~m}$ 


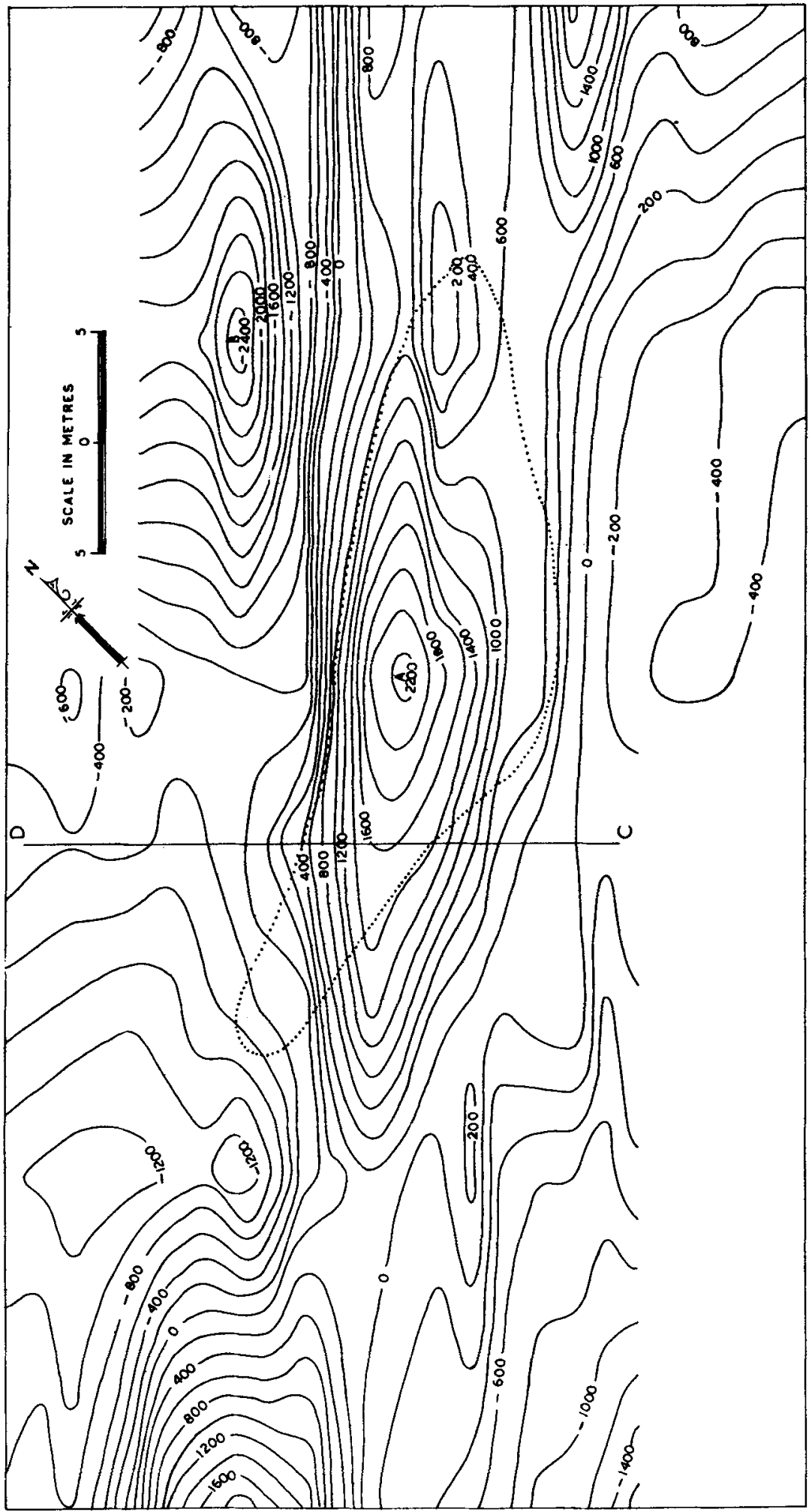

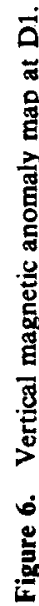




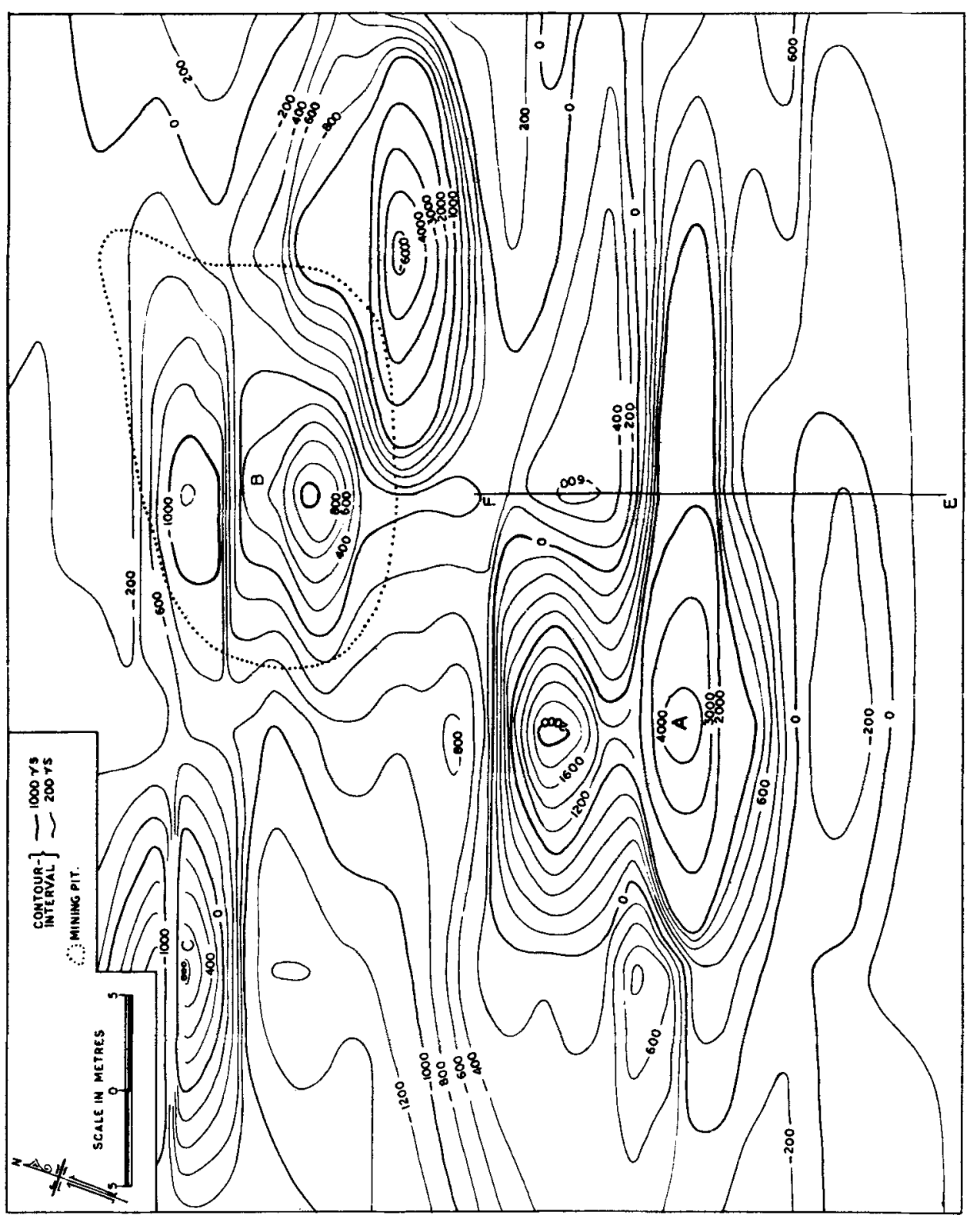

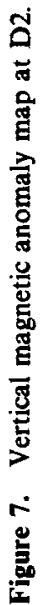




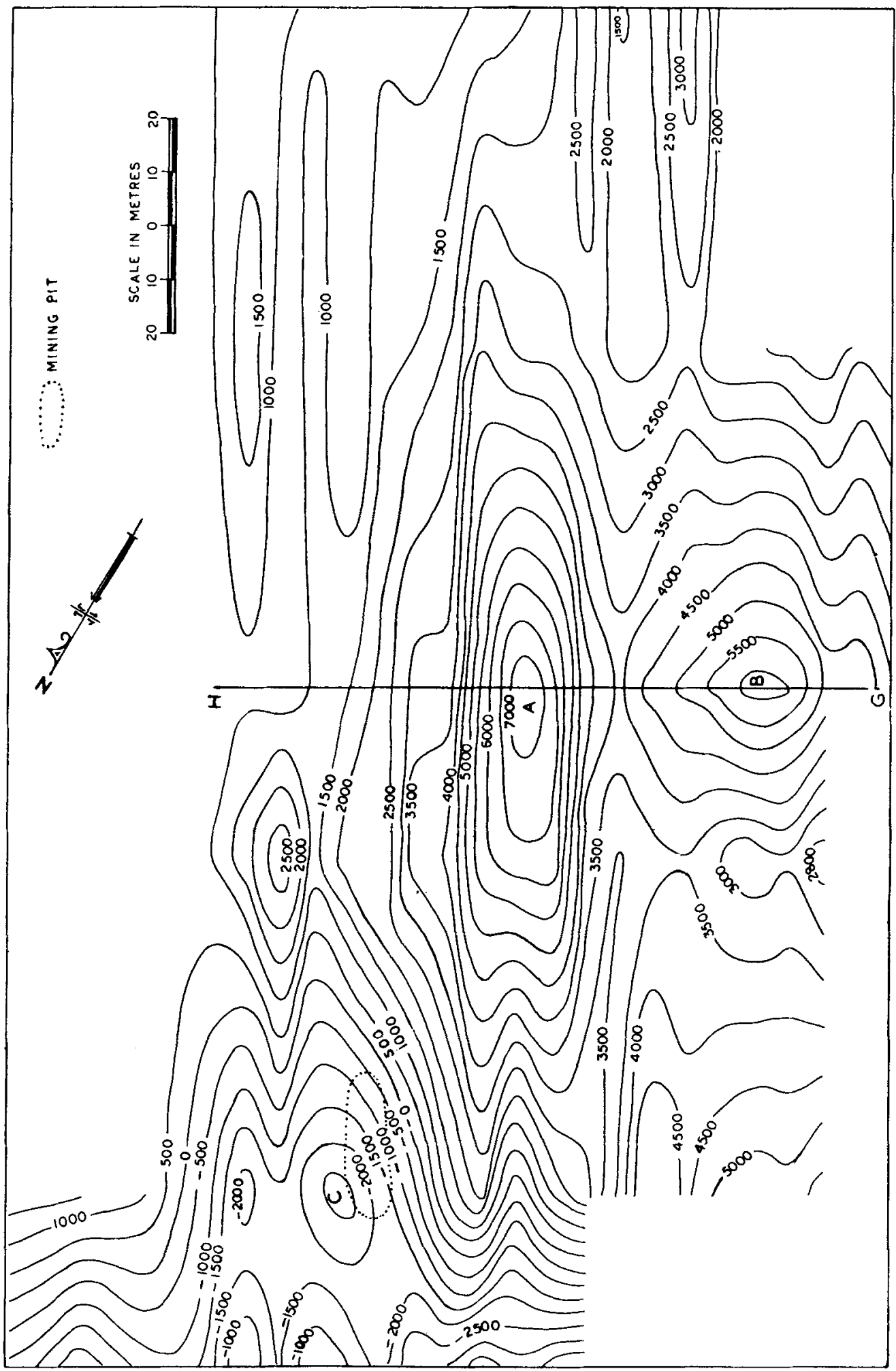

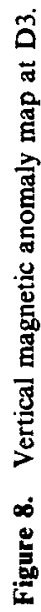




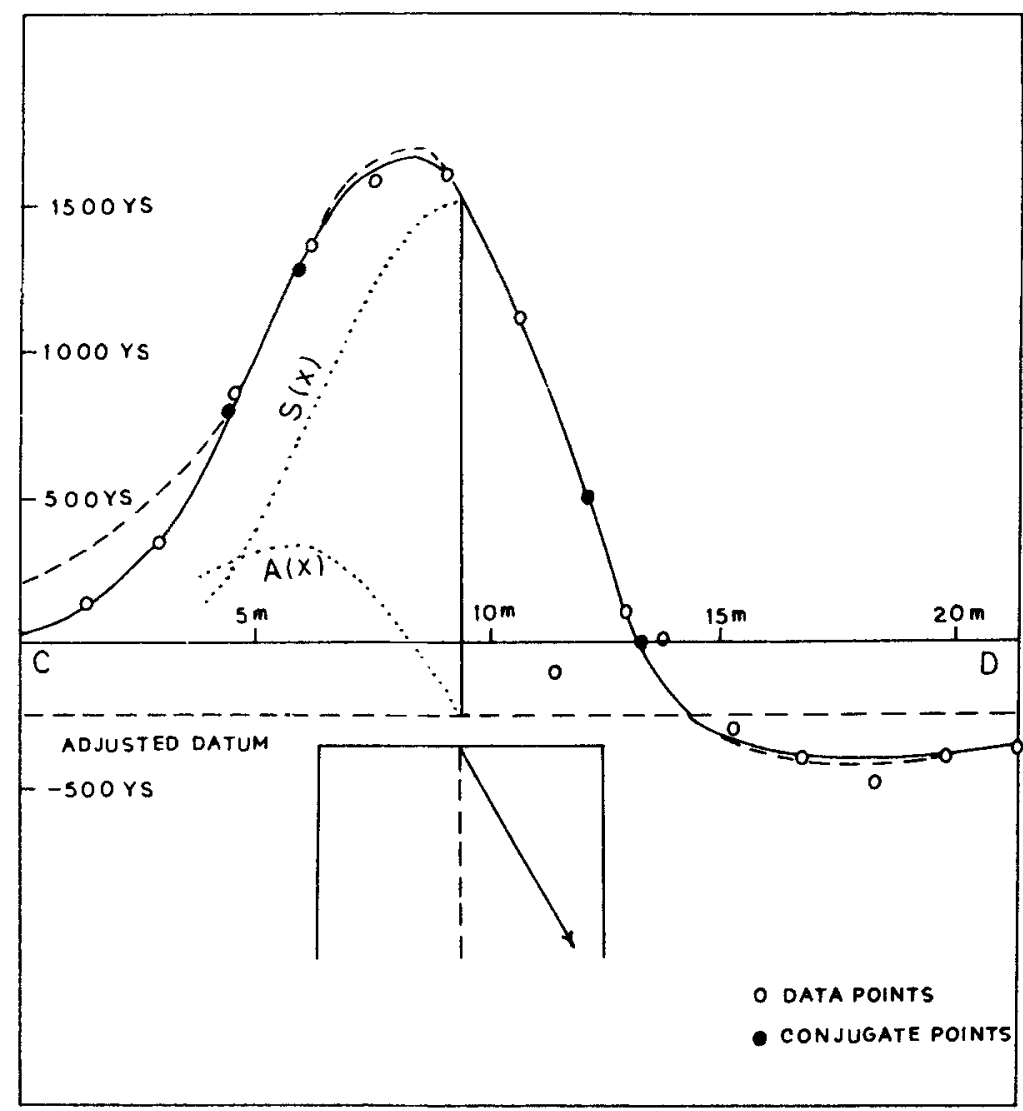

Figure 9. Profile CD.

and $29^{\circ}$ for depth width and $Q$ respectively were adopted. The discontinuous line in the figure is the theoretical curve corresponding to the above values and $5.3 \times 10^{-3} \mathrm{emu}$ for the intensity of magnetisation. Profile EF (figure 10) was plotted to interpret the thindyke-like anomaly in figure 7 . The anomaly band is narrow and the profile across it is sharp with steep flanks. The profile appears to represent a body of limited depth extent. The geological dips are nearly vertical. The curve EF was therefore analysed by Banerjee's (1972) method for thin vertical dykes of finite depth extent. The results are depth to top, $1.5 \mathrm{~m}$; depth to bottom, $5.8 \mathrm{~m}$ and $Q, 46^{\circ}$. A theoretical curve corresponding to the deduced parameters is shown as a discontinuous line exhibiting the close match between the two. It is believed that the ore formations at D1 and D2 belong to a single ore band. Two profiles were run between the two localities, D1 and D2, to ascertain continuity of the ore. They exhibit shapes and amplitudes similar to those of profile CD.

The principal profile GH (figure 11) across the anomaly pattern at D3 (figure 8) runs roughly from Sw to NE. It exhibits two features: the one towards NE corresponds to the elongated contour pattern and the other to the nearly circular pattern. From its low gradient the sw feature may be inferred to be due to a deeper-seated ore clot or a mineral concentration in the host rock. The former feature was analysed as a dyke anomaly. The 


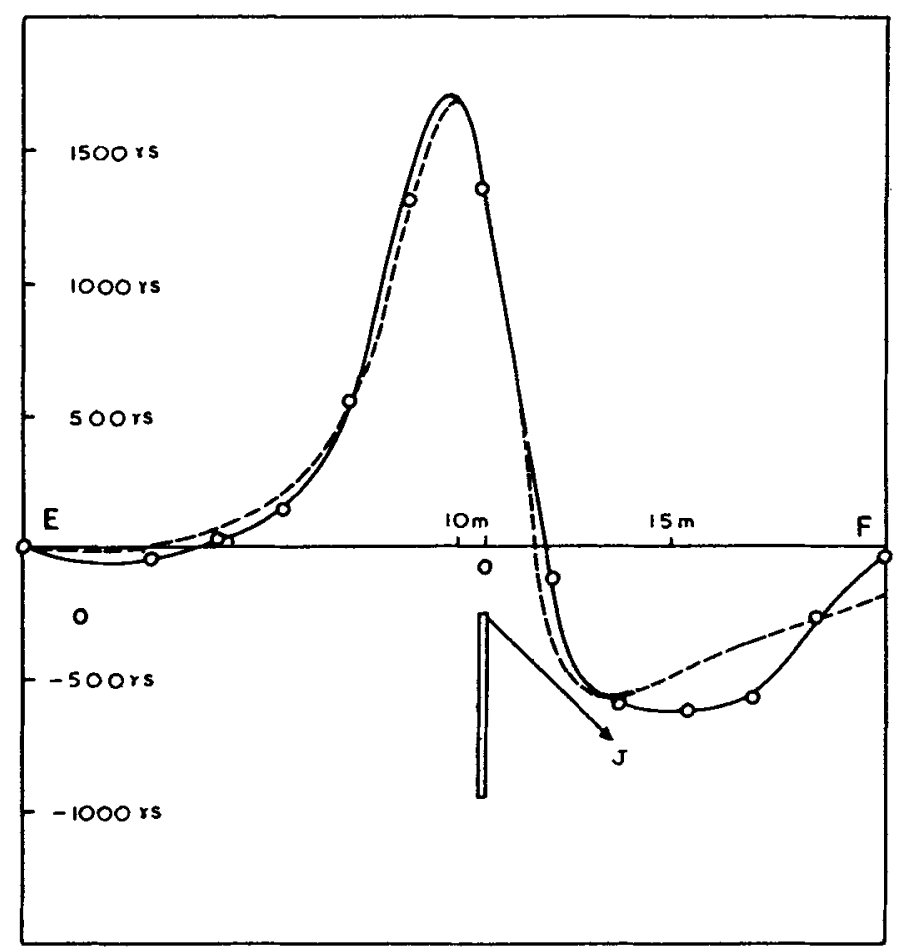

Figure 10. Profile EF.

datum is selected on the basis of the trend explicit in the curve. As was also observed at Addatigala and D1 the profiles exhibit weak minima and are bound to be masked or influenced by the adjacent anomalies requiring the curve to be smoothed in the region of the minimum. The contribution of the antisymmetric component, as shown in the figure, was very small. The results of interpretation of the symmetric component are: depth, $4.9 \mathrm{~m}$; width $15.5 \mathrm{~m}$ and $Q, 10^{\circ}$. For matching the theoretical curve, shown as a discontinuous line, corresponding to the above values an intensity of magnetisation of $10.5 \times 10^{-3} \mathrm{emu}$ is required.

At Tekuru the magnetometric observations were made on Enukonda hill along traverses at $\mathbf{N} 330^{\circ} \mathrm{E}$ spaced at $30 \mathrm{~m}$. The observations were at $3 \mathrm{~m}$ intervals. The anomaly map is presented in figure 12 . The area covered by the map is traversed by a stream-let course on both sides of which the elevation increases. Towards wNw is a practically flat ground. In general the elevation decreases towards NNE. In the sw part the country rocks outcrop. The positive anomaly contour of $200 \gamma \mathrm{s}$ (at $\mathrm{A}$ in the figure) is near a small trial pit (which evidently penetrates the iron-ore formation) almost on the bed of the streamlet. The anomaly increases in its negative magnitude towards north. This is believed to be the effect of topography. On sw where the rock formations are exposed the anomalies show steep gradient. The $1000 \gamma \mathrm{s}$ anomaly corresponds to the position of the projecting country rock formation. The low gradients towards east and SE may be due to the thick soil cover. The maximum anomaly observed near the trial pit, i.e. at the nearest approach to the ore on the stream bed, was $330 \gamma \mathrm{s}$. The anomaly due to the ore is not readily discernible probably due to the high magnetic nature of the 


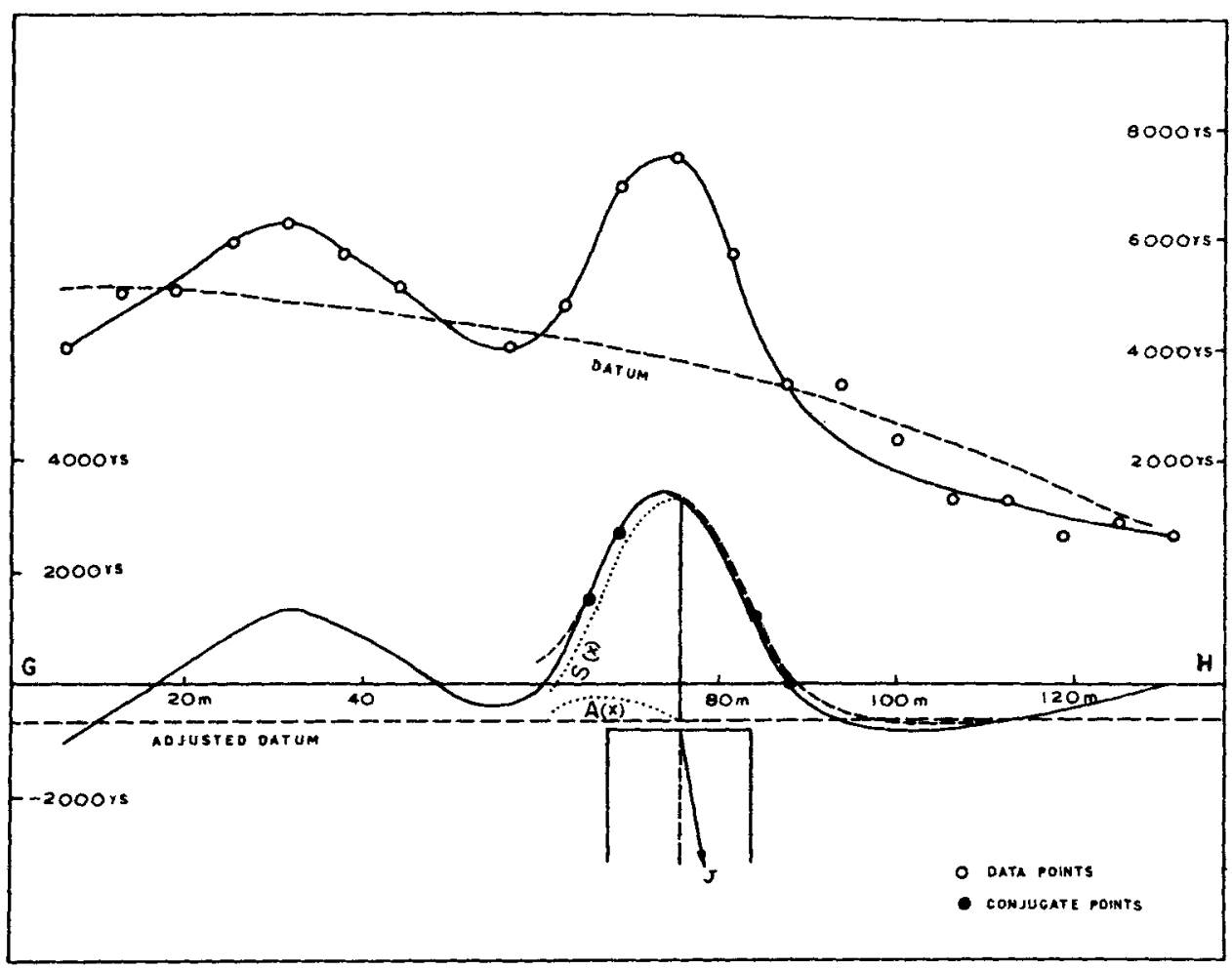

Figure 11. Profile GH.

country rock and also a limited depth extent of the ore. The country rocks, mostly khondalite gneisses, have NRM of about $3.7 \times 10^{-3} \mathrm{emu}$ and magnetic susceptibilities of about $2.5 \times 10^{-3}$ emu.

The profile IJ (figure 13) was chosen for analysis and the datum trend, which is very clear from the profile, was subtracted. The anomaly feature differs in its shape and amplitude from those of the other areas. The shape does not warrant the use of a dyke model. It is similar in shape to the vertical prism anomaly curves (Hjelt 1972). The country rock formations exposed on the stream bed suggest a structural control with vertical dips. Though there are many schemes of interpretation for prism anomalies they are not readily applicable for all field situations. In the analysis of the present profile it was matched with theoretical curves of a prism model obtained indirectly from dyke anomalies. The ore bands in the other areas, except where they were mined, are at shallow depths. So a depth of $4.6 \mathrm{~m}$ and a width of $16 \mathrm{~m}$ was assumed for the ore. Theoretical vertical magnetic anomalies of two infinite, vertical, $16 \mathrm{~m}$ wide dykes one buried at a depth of $4.6 \mathrm{~m}$ while the other at $7.6 \mathrm{~m}$ were calculated for $Q$ values ranging between $0^{\circ}$ and $90^{\circ}$. The anomalies due to the deeper dyke were subtracted from those of the shallower one to obtain the prism anomalies. The resulting curves are shown in figure 14 , with distance normalised by half width $(b)$ as abscissa. Of them the curve for a $Q$ value of $10^{\circ}$ seems to be similar to the anomaly. The anomaly in figure 13 matches with the mirror image of the theoretical curve about the anomaly axis. The match requires an intensity of magnetisation of $5 \times 10^{-3} \mathrm{emu}$. The body parameters of the prism model amount to depth: $4.6 \mathrm{~m}$, width: $18 \mathrm{~m}$, thickness: $3 \mathrm{~m}$ and $Q=-10^{\circ}$. 


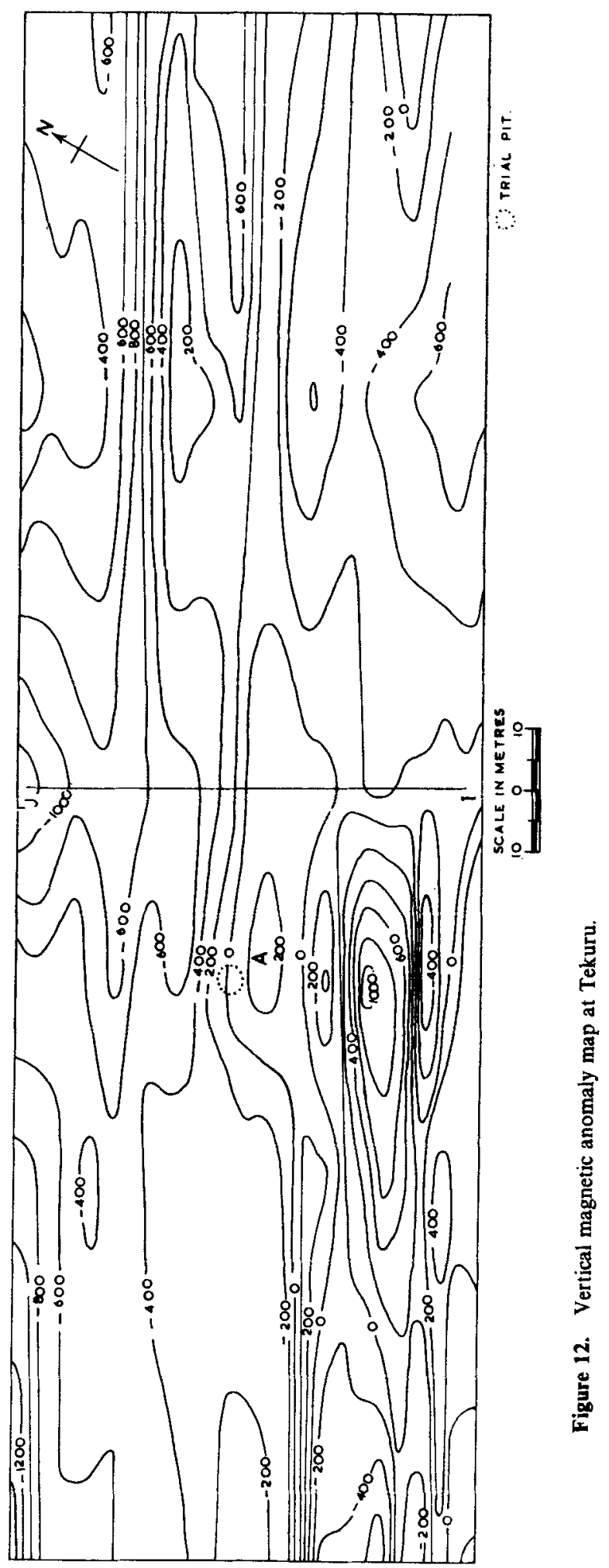




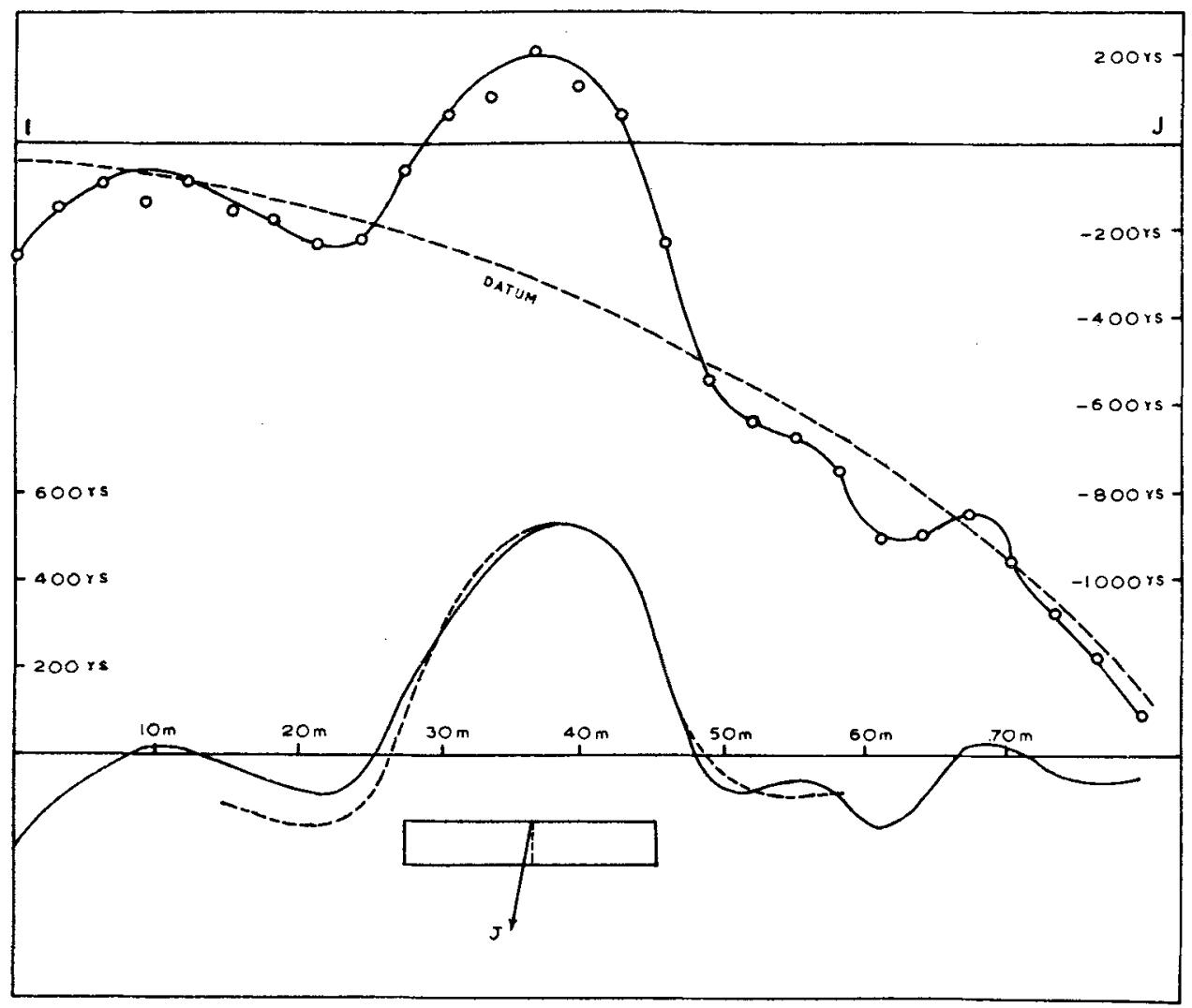

Figure 13. Profile IJ.

\section{Discussion}

The results of interpretation are given in table 1 . In most cases the theoretical anomaly curves agree with field curves. As can be seen from the table, most of the ore bands are at depths less than $5 \mathrm{~m}$. In the case of profile $\mathrm{AB}$, of Addatigala, a higher depth was obtained. The ore band at Addatigala has the largest width and that at D2 of Devipatnam the smallest. The other ore bands have intermediate widths. The bands at D2 and Tekuru have very small depth extents.

The fourth column in table 1 gives the angle $(Q)$ made by the magnetisation vector with the body sides in the profile plane. The angles obtained, with the infinite dyke model, are between $10^{\circ}$ and $29^{\circ}$. These small $Q$ values result in steep inclinations of magnetisation which are listed in the fifth column. In case the magnetisation is mostly induced, the inclination is expected to be close to the effective inclination of the geomagnetic field which can be obtained by taking into account the strike of the body $(\alpha)$ and inclination of the geomagnetic field $\left(I_{0}\right)$ from the relation (Gay 1963):

$$
\tan \left(I_{0}^{\prime}\right)=\tan I_{0} / \sin \alpha .
$$

The effective inclinations thus obtained are included in the table. As is evident the 


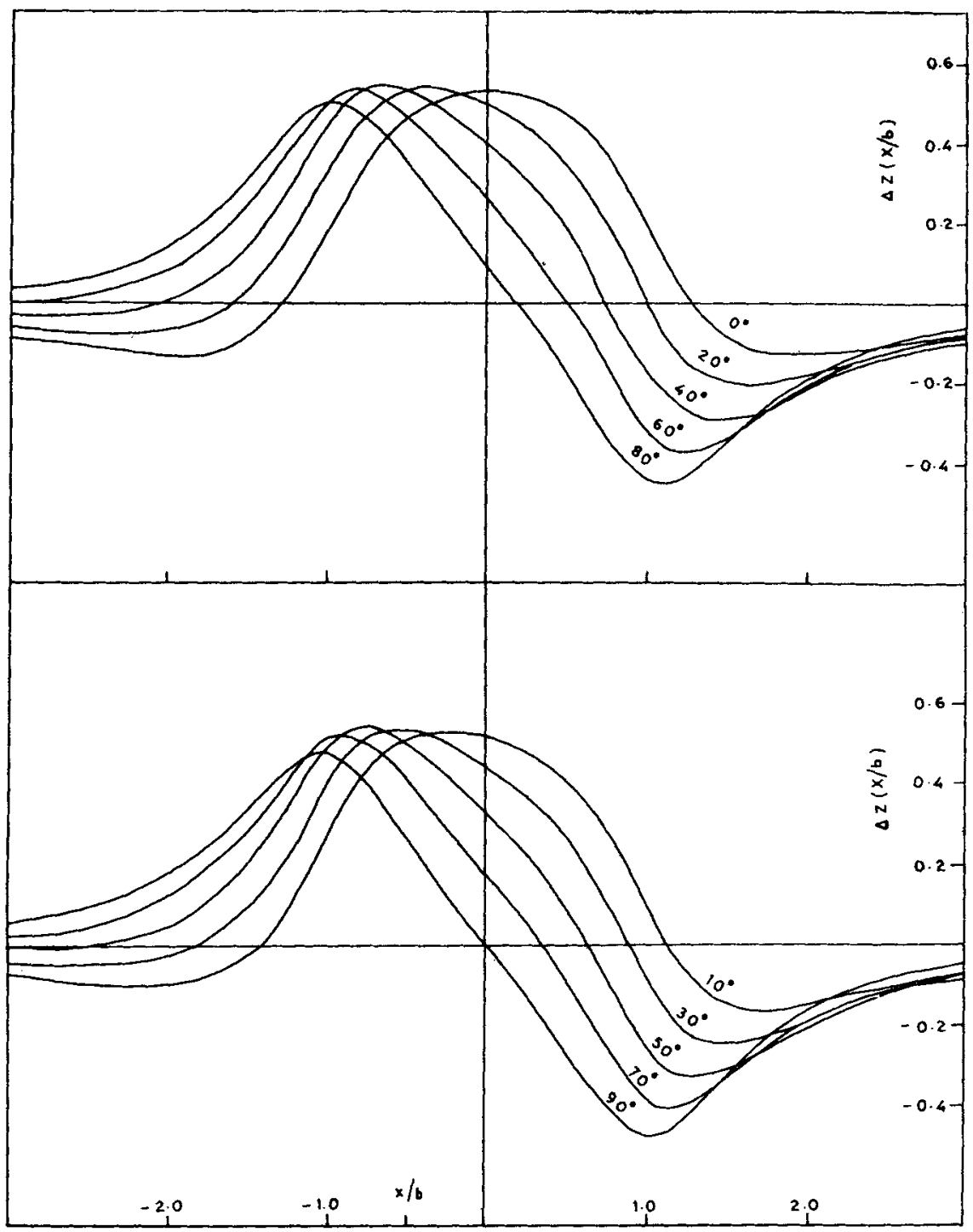

Figure 14. Theoretical anomaly curves for the prism model.

effective inclinations are quite different from the inclinations of magnetisation $(\phi)$. From the large differences between $\phi$ and $I_{0}^{\prime}$ it may be concluded that the natural remanent magnetisation (NRM) of the ore is different in its direction from, and stronger than, the induced magnetisation. This conclusion was supported by the laboratory measurements (Lakshmipati Raju 1977).

The intensities of magnetisation deduced by way of interpretation range from $5 \times 10^{-3}$ to $10.5 \times 10^{-3} \mathrm{emu}$ (table 1 ). In the laboratory NRM measurements were made on samples in which magnetite occurs as irregular bands and also on enriched ore samples. The NRM values (table 2) of the two together cover a wide range. The average for low values is $5 \times 10^{-3} \mathrm{emu}$. The intensities of magnetisation listed in table 1 agree 
Table 1. Results of interpretation of profiles.

\begin{tabular}{lcccccc}
\hline Profile & $\begin{array}{c}\text { Depth } \\
(\mathrm{m})\end{array}$ & $\begin{array}{c}\text { Width } \\
(\mathrm{m})\end{array}$ & $Q^{\circ}$ & $\phi^{\circ}$ & $I_{0}^{\circ}$ & $\begin{array}{c}\mathrm{J} \times 10^{3} \\
(\mathrm{emu})\end{array}$ \\
\hline AB & 10.7 & 27.1 & 19 & 101 & 22 & 8.6 \\
CD & 2.1 & 6.0 & 29 & 61 & 24 & 5.3 \\
EF & 1.5 & - & 46 & 44 & 21 & - \\
& 5.8 & - & - & - & - & - \\
GH & 4.9 & 15.5 & 10 & 80 & 36 & 10.5 \\
IJ & 4.6 & 18.0 & -10 & 100 & 23 & 5.0 \\
& & 3.0 & & & & \\
\hline
\end{tabular}

$Q$ : Angle between the body side and the magnetisation in the profile plane; $\phi$ : Inclination of magnetisation in the profile plane; $I_{0}^{\prime}$ : Effective inclination of the geomagnetic field; $a$ : Depth to the bottom; $c$ : Thickness.

Table 2. NRM values of iron-ores.

\begin{tabular}{lcc}
\hline & $\begin{array}{c}\text { Range of NRM } \\
J \times 10^{3}(\mathrm{emu})\end{array}$ & $\begin{array}{c}\text { Number of } \\
\text { samples }\end{array}$ \\
\hline Samples in which magnetite & & \\
occurs as irregular bands & $1.6-9$ & 14 \\
Enriched ore samples & $13-50$ & 2 \\
& $25-102$ & 3 \\
& $123-139$ & 3 \\
& $1021-2658$ & 2 \\
\hline
\end{tabular}

with the lower range of values and the anomalies can be attributed to the iron-ore.

From the apparently undisturbed nature of the anomaly map at D1 of Devipatnam it may be surmised that the ore as well as the host rock have a uniform magnetisation. At D2 the mineralised zone appears to have branched off in two directions. The analysis of profile EF (figure 10) indicates that the ore is in the form of a thin vertical dyke with small depth extent. Two profiles were run between D1 and D2 which indicate continuity of the ore band. Towards D2 the depth extent of the ore decreases. At D3 the magnetic background seems to be very high. While analysing profile $\mathrm{GH}$ (figure 11) it was observed that the datum level, after 'adjustment', is at roughly 4,500 $\gamma \mathrm{s}$ above the base value. At Tekuru the anomaly is not prominent. This is believed to be partly due to the high magnetic background and partly due to small depth extent of the ore.

The results of interpretation of profile IJ may not be unambiguous. A different set of values for the parameters may give rise to a theoretical curve of equally good fit. But the parameters adopted serve the purpose of indicating the order of dimensions of the ore band. More important than that, they indicate the order of minimum dimensions of the ore bands that can be successfully delineated in terrains of such high magnetic background. It is quite likely that such conditions of background prevail even in the Eastern Ghats or other such beits. It is concluded that in such areas it is only the high grade magnetite ore bands of considerable depth extent that can be successfully delineated by the magnetic method. 


\section{References}

Banerjee B 1972 Geophysics 37963

Barnes V E and Romberg F 1943 Geophysics 832

Bath G D 1962 Geophysics 27627

Bean R J 1966 Geophysics 31963

Bhattacharya B K 1964 Geophysics 29517

Bhattacharya B K 1966 Geophysics 3174

Bourret W 1949 Econ. Geol. 44732

Broderick T M 1918 Econ. Geol. 1335

Bruckshaw J M and Kunaratnam K 1963 Geophys. Prosp. 11510

Cook K L 1950 Geophysics 15667

Egyed L 1948 Geophysics 13437

Gaucher E H S 1965 Geophysics 30762

Gay S P Jr 1963 Geophysics 28161

Gay S P Jr 1967 Mining geophysics 1 (Oklahoma: SEG) 429

George L W 1967 Mining geophysics 1 (Oklahoma: SEG) 391

Grant F S 1972 Geophysics 37647

Grant F S and Martin L. 1966 Geophysics 31135

Grant F S and West G F 1965 Interpretation theory in applied geophysics (New York: McGraw Hill)

Hjelt S E 1972 Geoexploration 10239

Hutchison R D 1958 Geophysics 23749

Jung K 1953 Geophys. Prosp. 129

Koulomzine Th, Lamontagne $\mathrm{Y}$ and Na deau A 1970 Geophysics 35812

Koulomzine Th and Masse L 1947 AIME Tech. Pub. No. 2260

Lakshmipati Raju A 1977 Magnetic studies on some iron-ore deposits of Godavari districts, Andhra Pradesh, India, Ph.D. thesis, Andhra University, Waltair

Moo J K C 1965 Geophys. Prosp. 13203

Mooney H M and Bleifuss R 1953 Geophysics 18383

Mumme W G 1963 Geophysics 28593

Narasayya B L 1970 Mineralogy of chromite, magnetite and apatite deposits of parts of Eastern Ghats, Andhra Pradesh, India, Ph.D. thesis, Andhra University, Waltair

Paul P C, Bhanumurthy Y R and Jagannadhan M 1971 Rec. Geol. Surv. India 10331

Paul R A 1967 Mining geophysics 1 (Oklahoma: SEG) 418

Powell D W 1967 Geophys. Prosp. 15208

Rao B S R and Murthy I V R 1967 Pure Appl. Geophys. 68124

Rao B S R, Radhakrishnamurthy I V and Subba Rao Y V 1974 Indian J. Meteorol. Geophys. 25493

Ray S 1967 Proc. Symp. U.M.P. Hyderabad 249

Reford M S 1964 Geophysics 29532

Seguin M K 1968 Can. Min. Metal. Bull. 950

Seguin M K 1971 Geophys. Prosp. 19459

Sharma P V 1966 Pure Appl. Geophys. 6489

Singh C L and Avadh Ram 1971 Pure Appl. Geophys. 85283

Sriramadas A 1961 Mahadevan Volume 130

Vacquier V, Steenland N C, Henderson R G and Zeitz I 1951 Geol. Soc. Am. Mem. 47

Vincenz S A 1955 Geophysics 20593

Webb J E 1967 Mining geophysics 1 (Oklahoma: SEG) 379 